\title{
Integrating Commercial Solar Panels in the Physics Curriculum
}

\author{
Nicole L. Ackerman Amy J. Lovell, Meghan Franklin $\left.\right|^{\text {f }}$ Rebecca Cupp, \\ Yijun (Emma) Wan, Victoria Wood, Connor Day, and Eli Whisnant \\ Department of Physics and Astronomy, Agnes Scott College, 141 E. College Ave, Decatur, GA 30030
}

(Dated: September 3, 2015)

\begin{abstract}
Agnes Scott College has a significant number of sustainability initiatives, including a hydrogeothermal HVAC system and five solar photovoltaic arrays. The Physics and Astronomy department is in the process of integrating alternative energy into our curriculum and public outreach activities. During Laboratory Physics (PHY311), two student teams pursued self-designed projects to model the efficiency of the $6 \mathrm{~kW}$ solar array installed at a fixed tilt on the flat roof of the college Observatory. During the summer of 2015, two student research scholars constructed a movable mount and data acquisition system for a stand alone panel identical to those on the roof, to allow control and recording of individual variables such as sun angle, temperature, and other weather conditions. In future years, students will learn about the solar panels in Analog Electronics (PHY242) and present solar power to K-12 school groups touring our Observatory.
\end{abstract}

PACS numbers: 88.40.hj, 01.50.Pa, 84.60.Jt

Keywords: Sustainability, Experiments, Photovoltaic cells

\section{INTRODUCTION}

Colleges, students, and society as a whole are increasingly interested in sustainability and "green" technology. The recent Green Technologies and Practice survey of the U.S. Bureau of Labor Statistics found over 800,000 workers who spent over half of their time involved in green technologies and practices, including 32,000 in the life, physical, and social sciences 1 . The United Nations declared the period from 2005-2014 the U.N. Decade of Education for Sustainable Development (DESD), reflecting the global prioritization of this issue. The 2012 DESD report found that institutions of higher education "are beginning to reorient their education, research, operations and community outreach activities towards sustainability, 2 .

Agnes Scott College has a history of sustainability initiatives such as a greenhouse gas inventory (since 2008), campus composting (2009), a water audit and plan (2008), a revolving fund specifically for green initiatives (2012), and a commitment to achieving LEED Silver or higher on new construction or major renovations (2007). The 2013-2014 renovation of Campbell Hall achieved LEED Gold certification and included a hydro-geothermal HVAC system. In 2014 and 2015, five separate photovoltaic arrays were installed throughout campus. Four of the panels are part of Georgia Power's Advanced Solar Initiative. In addition to the infrastructure initiatives, the college has offered a minor in Environmental and Sustainability Studies since 2009, sustainable internship opportunities for students, and the Azalea Workshop to encourage faculty to include environmental studies and sustainability issues and themes in courses throughout the curriculum. Having a sustainable campus, sustainability-focused academic programs, and interdisciplinary offerings are all parts of a comprehensive sustainability education strategy 3 .

Student interest, location, and content alignment have motivated the integration of green technologies into the physics curriculum. In 2013, a unit on geothermal heating and cooling was included in Introductory Physics while the hydrogeothermal HVAC system was being installed in the Science

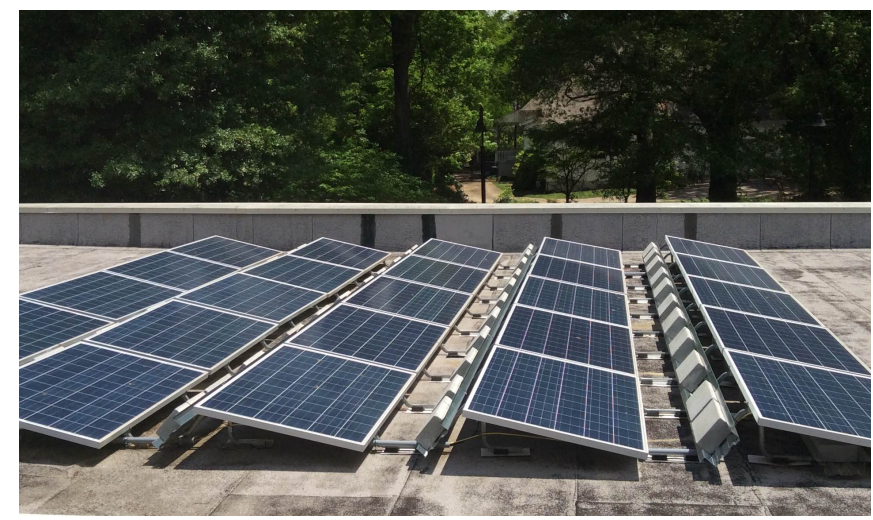

FIG. 1. This array is located on the rooftop of the Bradley Observatory at Agnes Scott. The photo is taken facing East, showing all 24 panels.

Quad. More recently, the Bradley Observatory Solar Array has been integrated into astronomy and physics laboratory experiments. While it is the smallest, it is the only array where the produced power is not fed back into Georgia Power's grid and where education is a primary goal. The array serves as additional instrumentation that can be used in concert with other devices such as LIDAR (Light Detection and Ranging) and a weather station that are already located at the Observatory.

The commercial panels have provided experimental physics scenarios that differ from what is typically provided in lab. In the context of our advanced lab course, the photovoltaic panels increase breadth and provide the opportunity for a variety of open ended measurements, both considered important features of this type of course ${ }^{4}$. The specific activities performed may be unusual for an advanced lab course, but the lab provides many opportunities to develop skills in line with the AAPT recommended learning outcomes for advanced lab courses 5 .

\footnotetext{
2015 BFY Proceedings, edited by Eblen-Zayas, Behringer, and Kozminski; Peer-reviewed, doi:10.1119/bfy.2015.pr.001

Published by the American Association of Physics Teachers under a Creative Commons Attribution 3.0 license.

Further distribution must maintain attribution to the article's authors, title, proceedings citation, and DOI.
} 


\section{SOLAR PANEL INSTALLATION}

In January of 2015, a $6 \mathrm{~kW}$ solar array was installed at the Bradley Observatory at Agnes Scott as shown in Fig. 11. This array is comprised of 24 ReneSola JC250M-24/Bbv modules, which utilize polycrystalline silicon cells. The incline of the panels is fixed at $11.9^{\circ}$ with a $180^{\circ}$ azimuth (due south). This array is used to partially power the Observatory and is tracked via SMA Solar Technology's SunnyPortal web interface. The data, available in both tabulated and graphical forms, track power production in 15 minute increments.

In addition to the array, one "stand alone" $250 \mathrm{~W}$ panel is available. This panel is neither mounted nor integrated into the electrical system, enabling it to serve as an experimental system that can be modified and directly measured.

Additional instruments are available at the Observatory, including a WeatherLink weather station and LIDAR. The WeatherLink equipment is located two feet from the solar panel array with sensors located about seven feet above the height of the solar panels. This instrument records all of the meteorological information, including solar radiation and temperature. Data is logged to a computer interface hourly. The Eye Safe Research Lidar (EARL) is a $523.5 \mathrm{~nm}$ atmospheric LIDAR system with sensitivity from 0 to $15 \mathrm{~km}$.

\section{STUDENT PROJECTS}

Students have performed research involving the solar panels in two different contexts, with two groups designing experiments for their capstone projects in our advanced laboratory course. A separate pair of students worked on a multifaceted summer research project utilizing the solar panel array and the stand alone panel. The following sections outline the context and nature of these projects. The activities that the students performed are presented in Table I in the context of the AAPT recommended learning outcomes for advanced lab courses 5 .

\section{A. Laboratory Physics: PHY311}

Laboratory Physics (PHY311) serves as the college's advanced lab physics course. This course was offered in 2011 and was re-developed for spring of 2015, with the expectation that it will be offered every two years. Eight students were enrolled in the course. They were introduced to modern experimental techniques, including keeping a formal lab notebook, computer-aided data acquisition, error propagation, and Python-based data analysis. Students worked in pairs on six laboratory experiments plus a final "capstone" lab.

Students designed their own experiment for their final lab, unlike the previous labs which utilized lab manuals and specified experimental questions. Students were provided with ideas for their final labs, effectively a list of available equipment. After submitting their preference for what measurement they wished to make, students completed two scaffolding assignments before beginning the lab itself.
The first assignment was a brief literature review related to their experiment. This assignment coincided with a workshop session at the library on database usage and bibliographic tools. Each student had to identify three papers related to their intended capstone lab, access and read the paper, and explain why the paper is relevant to their work. Previous lab experiments had associated recommended literature, so the capstone lab was the first for which the students were wholly responsible for identifying their own background literature.

The second assignment, completed with both students working together, was a detailed proposal for their capstone lab. Students were asked to address a number of topics in narrative form, including the apparatus, measurement, necessary calibrations, expected sources of uncertainty, intended analysis, and possible challenges. Detailed comments were provided to assist students in optimizing their equipment, technique, and analysis.

There were two scheduled three-hour lab sessions over a period of two weeks, but groups spent significant time outside of class on their experiments. The reports were due one week after the final scheduled session, which allocated time for them to complete the experiments and report after classes had ended. Reports were submitted individually, but all analysis steps could be completed with their lab partner.

One group (referred to as 311A in Table I) investigated the relationship between the solar incline angle of the panels and the efficiency of the panels. The theoretical ideal was calculated via a dot product between the normal vector from the panels' surface and position vector of the sun obtained using the NASA JPL Solar System Dynamics service, HORIZONS ${ }^{6}$. The model was compared to data taken for the period of March 16 - April 16, 2015. To account for weather conditions, individual days were categorized into one of seven categories.

A second group (311B in Table $\mathrm{I}$ ), working independently from the first, chose to model output power as a function of temperature and incident solar radiation. This group began with a model of efficiency ${ }^{7}$ depending on temperature and performed a fit to test the model and determine the parameters for the Observatory solar array. This group used the solar radiation and temperature that were measured by the weather station. These environmental data were combined with the Sunny Portal report of the power output from the arrays for the period from April 29, 2015 to May 2, 2015.

\section{B. Summer Research}

During the summer of 2015 Agnes Scott began a new summer initiative to support faculty-student collaborative research in STEM fields funded by the Goizueta Foundation and the Frances Marx Shillinglaw Women in Science Endowment Fund. Two students, both rising Juniors who have completed the calculus-based Introductory Physics sequence, worked on a project related to the solar array.

These students began with making efficiency calculations for the 24-panel array, analyzing the entire period of data available since installation and working to understand any 
TABLE I. Example Solar Panel Activities Categorized by AAPT Focus Areas

\begin{tabular}{|c|c|c|c|c|}
\hline Focus Area & Activity & 311A & 311B & SU \\
\hline \multirow{5}{*}{ Constructing Knowledge } & $\begin{array}{l}\text { Combined measurements from multiple systems to construct a model of solar panel } \\
\text { efficiency }\end{array}$ & $\mathrm{X}$ & $\mathrm{X}$ & $\mathrm{X}$ \\
\hline & Defined research questions & $\mathrm{X}$ & $\mathrm{X}$ & $\mathrm{X}$ \\
\hline & Incorporated uncertainties into analytical model & $\mathrm{X}$ & $\mathrm{X}$ & \\
\hline & Revised research question based on available data/measurements & $\mathrm{X}$ & $\mathrm{X}$ & \\
\hline & $\begin{array}{l}\text { Interpreted plots of solar power versus time of day to test hypotheses about confounding } \\
\text { variables }\end{array}$ & & & $\mathrm{X}$ \\
\hline \multirow{4}{*}{ Modeling } & Interpolated and matched measurements recorded with different cadences & $\mathrm{X}$ & $\mathrm{X}$ & $\mathrm{X}$ \\
\hline & Employed equations for the local position of the sun to predict incident radiation & $\mathrm{X}$ & & $\mathrm{X}$ \\
\hline & Proposed reasons for disagreement between data and model & $\mathrm{X}$ & $\mathrm{X}$ & \\
\hline & Developed a shading model based on angular measurements of trees & & & $\mathrm{X}$ \\
\hline \multirow{6}{*}{ Designing Experiments } & Designed experimental procedure in collaboration with another student & $\mathrm{X}$ & $\mathrm{X}$ & $\mathrm{X}$ \\
\hline & Utilized existing literature in planning experiment & $\mathrm{X}$ & $\mathrm{X}$ & $\mathrm{X}$ \\
\hline & $\begin{array}{l}\text { Applied realistic constraints and safeguards to experimental design to be deployed } \\
\text { outdoors }\end{array}$ & & $\mathrm{X}$ & $\mathrm{X}$ \\
\hline & $\begin{array}{l}\text { Applied realistic constraints to experimental design, including limited budget, limited } \\
\text { number of sensors to track measurements, and need to protect electronic elements } \\
\text { from weather }\end{array}$ & & & $\mathrm{X}$ \\
\hline & Used initial data/calculations to design an automated measurement system & & & $\mathrm{X}$ \\
\hline & $\begin{array}{l}\text { Used initial data and efficiency calculations to design a measurement system that ad- } \\
\text { dressed the timing and interpolation problems encountered in early tests }\end{array}$ & & & $\mathrm{X}$ \\
\hline \multirow{3}{*}{$\begin{array}{l}\text { Developing Technical and } \\
\text { Practical Laboratory Skills }\end{array}$} & Analyzed data in Microsoft Excel & $\mathrm{X}$ & & $\mathrm{X}$ \\
\hline & Measured open circuit voltage and closed circuit current using a digital multimeter & & & $\mathrm{X}$ \\
\hline & Analyzed and fit data in Python & & $\mathrm{X}$ & \\
\hline \multirow{4}{*}{$\begin{array}{l}\text { Analyzing and Visualizing } \\
\text { Data }\end{array}$} & Reconciled time stamps of data written in different formats or after glitches & $\mathrm{X}$ & $\mathrm{X}$ & $\mathrm{X}$ \\
\hline & $\begin{array}{l}\text { Computed real-time efficiency for the panel array by comparing theoretical and mea- } \\
\text { sured insolation with the power produced throughout the day }\end{array}$ & $\mathrm{X}$ & & $\mathrm{X}$ \\
\hline & Compared theoretical and measured values to estimate efficiency & $\mathrm{X}$ & & $\mathrm{X}$ \\
\hline & Tested different data visualization techniques & & & $\mathrm{X}$ \\
\hline \multirow{2}{*}{ Communicating Physics } & Worked in pairs & $\mathrm{X}$ & $\mathrm{X}$ & $\mathrm{X}$ \\
\hline & Wrote PRL-style lab report & $\mathrm{X}$ & $\mathrm{X}$ & \\
\hline
\end{tabular}

anomalies in the data. They discovered that the weather station had shifts in its timestamps due to power failures, causing misalignment in the data between the different systems. By measuring the angles to nearby trees, they identified times during the year when the panels would be partially shaded and found times when the weather station would be more shaded than the panels.

The students also designed a frame and data acquisition system for a stand-alone panel. The panel is mounted on a frame allowing for adjustable azimuth and elevation angle. It will have voltage and current measurements recorded via Arduino, with additional sensor readings for temperature and tilt. This system will provide further experimental opportunities, overcoming many of the challenges discovered by the PHY311 lab students.

\section{FUTURE EFFORTS}

Since the commercial array has only been available for one academic semester, much of the student work has focused on understanding what data is available and how the array can be studied. The results of the above-discussed student work will influence future student projects. The stand alone panel will be integrated into another physics course beginning this fall, and the department anticipates finding additional connections to courses and research.

\section{A. Analog Electronics: PHY242}

The college offers a two-semester electronics sequence, primarily taken by physics majors. The first semester (PHY242) focuses on Analog Electronics, while the second semester (PHY243) focuses on Digital Electronics with a culminating Arduino project. Although students enrolled in this sequence 
have some hands-on experience with simple circuits, many students have difficulty transitioning from ohmic devices to more general relationships between current and voltage. Photovoltaic cells have interesting I-V curves from which the ideas of power and load of a non-ohmic device can be studied. They can additionally serve as introductions to solid state devices and non-ideal power sources.

A new unit will be added to PHY242, transitioning from "familiar" circuits to solid state devices. Students will take measurements on the stand alone panel, measuring open circuit voltage, short circuit current, and interpreting the I-V curve to find the operating point for maximum power. This system will introduce them to the basics of solid state devices and should facilitate the understanding of transistors. Students have expressed difficulty in seeing how "basic" circuits connect with the real world; studying a commercial device should help connect electronic theory to the real world and encourage high quality learning .

\section{B. Observatory K-12 Outreach}

In addition to higher education for Agnes Scott students, the Bradley Observatory is host to about $1500 \mathrm{~K}-12$ schoolchildren and community outreach visitors. Our educational outreach programs, led by faculty and advanced students, address specific scientific concepts as spelled out in the Department of Education's Georgia Performance Standards (GPS). As the solar arrays on campus have grown, we have incorporated solar energy topics into our tours and observatory visits. This provides an opportunity for local schools to have scientifically-relevant field trips, even if they are not currently studying astronomy, and provides our advanced students excellent experience in public speaking. Student tour guides have the opportunity to prepare and present specific topics appropriate to the grade level of the visitors, but also to respond unscripted to visitors' questions, honing their skills in both formal and informal scientific communication.

\section{v. CONCLUSIONS}

The photovoltaic array and stand alone panel serve as a complement to the traditional experiments available in our labs. Students determine their own scientific questions where the result is not known before the experiment. They are honing their problem solving skills, finding ways to combine data from different sources, and accounting for a number of variables outside of their control. Comparing the home-built data acquisition system to the commercial product is a valuable lesson in calibration and the assumptions present in all measurements.

In the semester of work done with the commercial array, a number of challenges have been observed. The power reporting through Sunny Portal is not sufficient for many studies on its own. The data from the weather station has been invaluable though limited by hourly reporting. The size of the array leads to variations in shade, temperature, and other important parameters. These challenges introduce students to the true nature of doing experimental work, and the less-desirable constraints will be removed in the future by working with the stand alone panel. Utilizing both the array and stand alone panel will provide students with a system rich with experimental possibilities.

\section{ACKNOWLEDGMENTS}

R.C. and Y.W. are supported by the Agnes Scott STEM Scholars program. Jennifer Kaduck and Susan Kidd provided information on sustainability initiatives. Steve Chiariello of Inman Solar assisted with the direct solar panel measurements. Alix Valcin and David Smith provided engineering assistance.

\footnotetext{
* nackerman@agnesscott.edu

$\dagger$ Now at Department of Agricultural And Environmental Sciences, Tuskegee University, 1200 W. Montgomery Rd., Tuskegee Inst, AL 36088

${ }^{1}$ Bureau of Labor Statistics, Green Technologies and Practices Summary, Tech. Rep. USDL-12-1291 (U.S. Department of Labor, 2012).

2 Cathy Nolan, Shaping the Education of Tomorrow: 2012 Report on the UN Decade of Education for Sustainable Development, Abridged (UNESCO, 2012).

3 Mark Stewart, "Transforming higher education: a practical plan for integrating sustainability education into the student experience," Journal of Sustainability Education 1 (2010).
}

4 Jonathan F Reichert, "The advanced lab: Hallmark of an outstanding undergraduate program," American Journal of Physics 82, 181-182 (2014).

5 J. Kozminski et al., "Aapt recommendations for the undergraduate laboratory curriculum," http://www.aapt. org/Resources/upload/LabGuidlinesDocument_ EBendorsed_nov10.pdf(2014).

${ }^{6}$ California Institute of Technology Jet Propulsion Laboratory, "Horizons web-interface," http://ssd.jpl.nasa. gov/horizons.cgi

7 E Skoplaki and JA Palyvos, "On the temperature dependence of photovoltaic module electrical performance: A review of efficiency/power correlations," Solar energy 83, 614-624 (2009).

${ }^{8}$ Elizabeth Whitelegg and Malcolm Parry, "Real-life contexts for learning physics: meanings, issues and practice," Physics Education 34, 68-72 (1999) 